siderable scale have disclosed no fewer than nineteen occupation-levels, belonging to a culture which, though differing, resembles that of the Hittites of the Anatolian plateau closely enough to be considered akin to it. These levels overlie a civilization which would seem to be linked culturally with predynastic Egypt and Sumer. This indicates the incoming of Hittite culture in the fourth millennium B.c., thus antedating considerably the period usually assigned to the foundation of the Hittite capital on the Anatolian plateau. Further soundings in deeper levels have disclosed an even more considerable antiquity, in which this region was evidently a centre of no little cultural activity. Although the succession of painted pottery wares and stylized patterns reflect relationship with the oldest Mesopotamian styles, there is also evidence of local development lasting over a long period. In the lowest level a rich neolithic stratum has been found, similar to that of Sakje Geuzi, in which the most characteristic features are the use of obsidian, for weapons and tools, instead of flint, and a black pottery which is thin and highly finished.

\section{Viking Relic in the British Museum (Bloomsbury)}

THE acquisition of a remarkable example of Viking art-it is, in fact, considered to be the most remarkable Viking relic now in existence outside Scandinavia -was reported at the February meeting of the Trustees of the British Museum (Bloomsbury). It is a carving in oak of the head and neck of some beaked creature which formed either the figurehead or the stern-post of a Viking ship. Its precise purpose is at present uncertain. The animal motif, usually highly conventionalized, is one of the most familiar in the decorative art of the north European peoples in the first millennium of the Christian era; but of the zoomorphs, or animal-headed figures, which are known to have adorned the Viking ships, this is believed to be the only surviving example. It is almost four feet nine inches long, and is in the form of a rounded head on a long slender neck. The head curves smoothly into a parrot-like beak, which is open and shows teeth along the edge of the mandibles. The head is well poised on the slender neck, which is covered with a deeply carved lattice pattern, presumably representing feathers or scales. The history of its rediscovery is almost as remarkable as its character. It was found some two years ago during dredging operations in the River Scheldt. Other ship's timbers were brought up at the same time, but unfortunately were not preserved. The importance of the relic was so little appreciated that it was used for some time as a garden ornament. As it is known that the Island of Walcheren at the mouth of the Scheldt was long held by Danish Vikings at the beginning of the ninth century, this zoomorph is attributed to a Danish origin.

\section{Yorkshire 'Bygones'}

A collecrron illustrating the past cultural history of Yorkshire in the life of both country and town has been presented to the Corporation of York and housed in the old Female Prison, which has been converted into a museum for this purpose. The donor of the collection is Dr. Kirk of Pickering. The collection includes horse brasses, horseshoes, over one hundred insurance plates, and police truncheons, some of which were used in the Chartist and Bread riots. To these have been added fireplaces of various periods, weights and measures of all kinds and periods, and a collection illustrating the history of house lighting; all these exhibits are derived from the past custom of Yorkshire. One of the most instructive is the reconstruction of a Tudor street, some one hundred feet in length, in which are doorways, mounting blocks, shops and other features collected from various parts of the county. Parts of the Female Prison, which was built at the end of the eighteenth century, have been preserved in the original state. The Museum is not yet open to the public, but a private view for subscribers was held on February 5. Among the subscribers are the Carnegie United Kingdom Trust and the Joseph Rowntree Social Trust, Ltd., from each of which the sum of $£ 500$ has been received. The historical and geographical position of York makes it a peculiarly appropriate centre for a collection of this kind. The past cultural history of a county embodies much of interest to the student of archæology and ethnology, while custom illustrating its social history survived in a primitive form down to quite recent times, of which it is still possible to find traces in the remoter districts. In these matters, it is true, Yorkshire does not stand quite alone; and although the scheme for a national folk-museum for England seems for the time being to make little progress, it is none the less gratifying to note that local collections are being made before the material has entirely disappeared, as has been shown by recent correspondence in The Times.

\section{Hooke's Experiments on Combustion}

IN the issue of Ambix of December 1937, Dr. D. J. Lysaght publishes an interesting account of Robert Hooke's theory of combustion, which he outlined in "Micrographia" ( 1665 ) and amplified in his "Lampas" (1677) and "Cutlerian Lectures" (1679). Hooke's failure to impress his views upon the members of the Royal Society is attributed to his lowly social position, the simplicity of his conceptions, and the innate conservatism of the seventeenth-century mind. Hooke wrote only a scanty account of the experiments upon which he based his ideas, and Dr. Lysaght has done a useful service to historical chemistry by giving a critical discussion of these experiments, as transcribed in Birch's "History of the Royal Society" (1756-57) from the Royal Society's "Journal Book" (1661-87). Hooke's "many luciferous experiments" sufficed to demonstrate all the important facts bearing upon the problem of combustion. "The consumption of a selected portion of the air, the necessity for a continuous supply of this fluid, the formation of heat and light by the 'composition', the existence of solids with the essential constituent of the air 'fixed' in them and available for combustion, 
and the increase of weight on calcination must be admitted to be almost all the evidence required for the modern theory. These phenomena were linked up with those relating to respiration. The one fact that was not understood seems to be the part played by the air in calcination .. . and this deficiency prevented the complete synthesis that appears to have been so near at hand." Dr. Lysaght concludes that Hooke's work had the effect of postponing for a considerable time the adoption of the phlogiston theory of combustion.

\section{Unemployment in Colorado}

A sURvey of the Colorado labour market and its "relation to unemployment compensation", by E. R. Livernash of the Massachusetts Institute of Tech. nology, has been issued in the University of Colorado Studies (24, Nos. 3 and 4 ; 1937). The survey was undertaken in the summer of 1936, and indicates that outside the provisions of the Act there are 45,000 agricultural labourers unemployed and 21,000 domestic servants, as well as a considerable number of those working in trading establishments employing less than eight persons. Unemployment of long duration is regarded as inadequately compensated, this type of unemployment being particularly heavy in the steel, coal and constructional industries and in declining industries such as the southern coal field. The problem of exhausted-benefit unemployment may be of major importance. The recurrent drain of seasonal unemployment, however, may be unwise, as annual earnings are often adjusted on a competitive basis. Much cyclical unemployment appears as seasonal employment, and this may mean a considerable volume of ineligible unemployment in a bad depression. The difficulty seems to be that in future depressions unemployed individuals most in need of relief will find themselves in the exhausted-benefit and ineligible classes. The law may be putting a premium on shorttime recurrent unemployment. Mr. E. R. Livernash suggests that experience under the Act, enabling us to classify types of unemployment, may ultimately permit compensation being related more upon the incidence of unemployment, both in occurrence and duration.

\section{A Nature Reserve of Fossil Plants}

Prof. G. R. Wreland made an eloquent plea (Science, March 19, 1937), that will be endorsed by the botanists of all countries, for the creation of a national monument on the Black Hills, U.S.A., in which specimens of the remarkable cycadeoid fossils will be exposed in situ for study among their natural surroundings. The magnificent photographs of these specimens previously published by Prof. Wieland are evidence how effective such a display would be. His present arguments, indicating the striking parallelisms between these plants and the types discovered in the Carpathians and the Isle of Wight and Isle of Portland and elsewhere, and directing attention to their increased significance in view of the wide vistas on floral morphology in the Gymnosperms opened by the discovery of the marvellous petrified Araucarian forest of the Cerro Cuadrado in central Patagonia, reinforce very powerfully the case for expenditure of time and money in achieving an appropriate display of these unique fossils. The locality is described as very accessible; the horizon is perfectly defined and the quarrying necessary not extensive. It is very much to be hoped that Prof. Wieland's object will be attained and the United States thus obtain a national monument that would be quite unique in its character and clear evidence that that great nation appreciates the value of some of its most remarkable scientific possessions.

\section{London Teachers' Association}

At its annual conference held on February 12, the London Teachers' Association was addressed by its new president, Mr. S. Vanderhook, of Holden Street School, Battersea, on "Current Issues in Education" including, as "the most vital", reduction in the size of classes. The L.C.C. programme for 1938-41 contemplates a reduction of classes in junior schools to 42 and in infants' schools to 44, the standard for senior schools remaining at 40. As it is now twentyfive years since the L.C.C. initiated a scheme for reducing the size of infants' classes to 48 and senior classes to $40 \mathrm{Mr}$. Vanderhook may well call the new scheme a "small" step forward. A large part of the address has reference to the measures which are to come into operation next year for raising the permissible school-leaving age to 15. The Board of Education's Circular 1457 on this subject is discussed on the lines of the National Union of Teachers' memo. of December 1937. Mr. Vanderhook would, himself, use a short way in dealing with applications for exemption from further school attendance in order to accept "beneficial employment". He would reject them all ; for he holds that there is no employment which is beneficial for young persons of fourteen years of age.

\section{Destruction of Sea-Birds by Oil}

A LIVELY and informative discussion regarding the destruction of sea-birds by oil waste took place at University College, London, in May last, under the auspices of the University of London Animal Welfare Society, and the report of the meeting has just been published (ULAWS Monographs and Reports, No. 2a). Prof. N. K. Adam opened the discussion. A summary of Prof. Adam's special report has already appeared in NaTURE of July 17, 1937, p. 100. Many representatives of oil and shipping interests and naturalists took part in the subsequent discussion, the general tenor of which indicated that, in spite of legislation and a 50-mile limit for the discharge of oil, the amount of destruction was still very great, Prof. Adam putting the estimated death-roll of seabirds at from 10,000 to 200,000 a year. Only international action is likely to be effective in bringing this destruction to an end, and since the maritime nations are almost entirely opposed to the compulsory fitting of oil separators to vessels, efforts are being made to prohibit the discharge of waste oil in certain 